\title{
Virtual Exchanges: Fake Mobility or Unique Experiences
}

\author{
Timothy D. Gwillim¹, Irina I. Karimova ${ }^{2, *}$ \\ ${ }^{1}$ College of Arts, Science \& Education, Davidson County Community College, Lexington, North Carolina, USA \\ ${ }^{2}$ Department of International Cooperation, St. Petersburg State University of Telecommunications, St. Petersburg, Russia
}

Received October 1, 2020; Revised January 14, 2021; Accepted February 5, 2021

\section{Cite This Paper in the following Citation Styles}

(a): [1] Timothy D. Gwillim, Irina I. Karimova, "Virtual Exchanges: Fake Mobility or Unique Experiences," Universal Journal of Educational Research, Vol. 9, No. 2, pp. 373 - 379, 2021. DOI: 10.13189/ujer.2021.090213.

(b): Timothy D. Gwillim, Irina I. Karimova (2021). Virtual Exchanges: Fake Mobility or Unique Experiences. Universal Journal of Educational Research, 9(2), 373 - 379. DOI: 10.13189/ujer.2021.090213.

Copyright $\bigcirc 2021$ by authors, all rights reserved. Authors agree that this article remains permanently open access under the terms of the Creative Commons Attribution License 4.0 International License

\begin{abstract}
With the advance of COVID-19, many colleges and universities needed to find alternative ways to conduct international exchanges. Many international exchanges and activities were canceled due to the virus. Also, much attention was diverted away from international activities as many focused on changing their classes to online formats. Due to the authors participation in Fulbright programs, cooperation between St. Petersburg State University of Telecommunications (SPbSUT) and Davidson County Community College (DCCC) began. Despite the cancelations and challenges that were occurring, SPbSUT in Russia and DCCC in North Carolina continued to work together to provide international exchanges for their students. Through a series of virtual classes and topic based discussions, students developed cross-cultural awareness and momentum was gained for more collaborations. This study highlights the virtual exchanges that were developed, and gives quantitative and qualitative survey results about the collaboration. The main purpose of this report, based on research conducted by Russian and American colleagues, is to share the experience in establishing and developing global collaborations, and to involve educational and scientific institutions in international cooperation.
\end{abstract}

Keywords COIL, Virtual, International Exchange, Community College

\section{Introduction}

Cooperation between SPbSUT and DCCC started in 2019, when a group of administrators from the United States community colleges visited St. Petersburg for an intensive two-week seminar. Presentations on the educational system in Russia and different educational institutions were held during their stay. After the seminar, the administrators returned to the United States. The colleagues from SPbSUT and DCCC began communicating about collaborations and initiated collaborations on faculty and student exchanges. An annual action plan was developed by the two institutions and included various activities. These activities included participation in SPbSUT's International Festival of National Cultures and Summer School Programs on History, Culture and Architecture of St. Petersburg. Plans were also made for SPbSUT students to travel to the United States and participate in a summer school program on American Culture in North Carolina.

Conversations were also conducted to determine subject areas for student collaborations. Psychology, Sociology, History, and Cybersecurity were discussed, but the decision was made to begin the collaborations between English and Communications classes. In November 2019, the first joint class of English was undertaken online by SPbSUT and DCCC. The main goal of this event was to determine students' interest in intercultural activities, multidisciplinary studies and studying abroad. 
On the basis of the results obtained in the pilot class, the institutions continued Collaborative Online International Learning (COIL) in spring 2020. Twenty-six students from Russia and the U.S. attended. Five classes were held in April and May in which students presented on predetermined topics. This paper aims to provide analysis on participatory data, and some of the issues authors faced organizing the virtual exchanges.

Colleges and universities today, more than ever, need to ensure that their graduates have become global citizens. In no matter what field of study that a student may find themselves, they likely will need to know about cultures around them and cultures from around the world. Because of the global nature of all areas today, colleges need to globalize their curriculum so that graduates are ready to step out into the workforce.

\section{Study Abroad}

International activities, such as students studying abroad, are not new concepts. Study abroad has long been recognized as one of the most effective ways to successfully acquire an understanding of another culture. It has been one of the primary methods of raising cultural awareness among university students for quite some time. Even though faculty have included globalized information in classes, students are able to participate in authentic exchanges with those of another culture through study abroad.

Research on long-term study abroad has documented that the practice is beneficial for students. The research has "documented a variety of beneficial outcomes, including functional knowledge, personal growth, and cross-cultural awareness and interest" (Mapp, 2012, p. 728). Studies have also shown that study abroad has positive effects which include cultural appreciation, increased open-mindedness, greater understanding, and new perspectives (Fry et.al., 2009).

Although the research for study abroad has confirmed the practice to be effective for students in a variety of avenues, only a small percentage of students actually are able to study abroad. The low participation rate among students begs for faculty at colleges and universities to participate in other international activities in their classes.

COIL activities allow more students the opportunity to experience international activities. COIL exchanges have been occurring for quite some time. As an example, in 2001 a COIL exchange took place between students from Taiwan and the United States (Cifuentes \& Yu-chih, 2001). Students in this exchange used email to communicate and conduct activities, since much of today's live stream video technology was not prevalent (Cifuentes \& Yu-chih,, 2001). Even with the limited technology of the time, the study commented on how successful the exchange became. "As a result of their experiences, participants constructed elaborate understandings of the cultures of teaching and language learning" (Cifuentes \& Yu-chih, 2001, p. 11).

Although the practice is not a new idea, few often participate in COIL exchanges. As an example, one could look to the North Carolina Community College system. The North Carolina Community College system contains fifty-eight colleges. One of the mission statements of the state system is "to open the door to high-quality, accessible educational opportunities that minimise barriers to postsecondary education, maximize student success, develop a globally and multi-culturally competent workforce, and improve the lives and well-being of individuals" (NCCCS, 2020). In this mission statement the college system prioritizes a global education. A recent study was conducted that examined the international activities of the community colleges in North Carolina (Whatley, 2020). A survey was sent to the fifty-eight community colleges to gauge the international activities on the campuses. Of the forty-two colleges that responded to the survey, only three responded that some type of COILexchange was conducted on their campuses (Whatley, 2020).

\section{COIL Exchanges}

Although COIL exchanges are not the common practice to internationalize the curriculum in the community colleges of North Carolina and Russia(?), it should be considered more often. COIL exchanges create an excellent opportunity for institutions to engage more students in international activities. Study abroad is an excellent learning tool in which students can experience another culture and be forced to learn intercultural competence. Although study abroad is a great tool, many more students can participate in COIL exchanges.

COIL exchanges have shown to help students move from cultural ethnocentrism to cultural ethnorelativism (Asojo, Kartoshkina, Amole \& Jaiyeoba, 2019). In Asojo, Karoshkina, Amole, and Jaiyeoba's study (2019), COIL exchanges were conducted between interior design students from the United States and Nigeria. The "responses from both U.S. and Nigerian students indicated that they became much more aware and sensitive when designing projects for potential clients and providing feedback on each other's work" (Asojo, Kartoshkina, Amole \& Jaiyeoba., 2019). The study also highlighted that students commented on their development of cultural sensitivity and personal growth in recognition that cultural differences exist (Asojo, et. al., 2019).

In another study from 2019, students from South Africa and the United States participated in a COIL exchange centered around reducing waste in dental laboratories (Vahed \& Levine, 2019). In this COIL exchange students from different disciplines worked together to find solutions to a problem (Vahed \& Levine, 2019). In the study of the exchanges, Vahed and Levine (2019) found that students expressed a growing knowledge of different cultural practices and worldviews. 
In COIL exchanges students share coursework while getting to know each other. "This broadens and deepens their understanding of course content while building cross-cultural communicative capacity through academic and personal engagement with the perspective of global peers" (Guth, 2013, p. 2). The State University of New York (SUNY) began a COIL Institute in 2010. The goal of the institute was to support COIL exchanges. The institute supported twenty-one institutions in the United States as they developed COIL exchanges with foreign institutions (Guth, 2013). By following the exchanges, they found some common themes and difficulties that the partnered institutions had in common. One item that all of the institutions said that they learnt was that the institutions needed to be flexible (Guth, 2013). Technology may not work, students may experience frustration, and a variety of other things may come up.

Another challenge that may happen with COIL exchanges is that the students on either side may use colloquial vocabulary which may lessen understanding (Guth, 2013). Other subtleties in language also could dampen the exchanges. Students often need to be alerted to these regional phrases that the international partner may not understand.

In a world in which COVID-19 has caused a stoppage in international travel and a great change in education, COIL exchanges should become a part of institution's curriculum. A Quacquarelli Symonds (QS) survey on the corona virus and how the virus is affecting educational institutions detailed that $61 \%$ of the respondents answered that the corona virus will greatly affect their study abroad programs (QS Survey, 2020). The majority of students who answered the survey stated that they are planning on delaying their study abroad plans (QS Survey, 2020). With the knowledge of this fact, it becomes important that educational institutions look to COIL exchanges to allow their students the opportunity to experience other cultures even while travel is not recommended.

Many educational institutions are moving their coursework online due to the effects of the corona virus. COIL exchanges still allow for intercultural exchanges among students to happen even if all coursework moves online. In a world that is in rapid change due to the effects of the corona virus, COIL exchanges should become a standard method of conducting international activities.

\section{Research Data}

The purpose of this study was to determine the factors influencing the decision to participate in international exchange programs among students of the The Bonch-Bruevich Saint-Petersburg State University of Telecommunications (St. Petersburg, Russia), Davidson County Community College (Lexington, NC USA), and Fayetteville Technical Community College (Fayetteville,
NC USA). American and Russian students took part in joint classes on English and Intercultural Communication between November 2019 and May 26, 2020.

In order to complete the study, a survey was given to each student who had participated in the exchanges at the end of the academic year. Although participation in the survey was not required of the students a greater majority did participate. Twenty-six students responded to the survey. Sixteen of the respondents were students at Bonch-Bruevich Saint Petersburg State University of Telecommunications (SPbSUT). There were seven respondents from Davidson County Community College (DCCC), and three respondents from Fayetteville Technical Community College (FTCC).

When considering the gender of the students responding, the greater majority of the students were female (20 students). Five of the students responding to the survey were male, and one respondent classified themselves as other. This ratio of respondents was closely aligned to the ratio of all of the students who participated, since the majority of the students participating were females. One of the reasons for the imbalance of respondents due to gender is due to the fact that the SPbSUT students who attended the exchanges were from the school of humanities at the university. This school at the university has many more females enrolled than males.

When considering the age of the participants, the greater majority (20 students) were in the 18 to 24 years of age range, which is not surprising when considering university students. There was one student under the age of eighteen, and five students over 25 years of age. Both the younger and the older students were attending one of the community colleges (DCCC and FTCC). The younger student was still a high school student who was attending the college class as part of a dual enrollment program. Older students are not uncommon for community colleges. Traditionally the average age of students at community colleges hovers around twenty-eight years of age.

In trying to determine if the exchanges led to growth of the students, it was important to consider if the students had participated in this type of COIL exchange previously. When asked about previous participation, $80.8 \%$ of the respondents had not previously participated in any type of COIL exchange. The fact that most of the participants had not experienced any type of COIL exchange activity is important when considering the following findings of the survey.

After participating in the exchanges, all of the students stated that they agree $(23.1 \%)$ or strongly agree $(76.9 \%)$ that these types of cultural exchanges should be in college curriculums. It is interesting that the greater majority of the students had not previously participated in these types of exchanges, but all felt that they should be included in the curriculum. This highlights the fact that students did enjoy meeting and speaking with other students from another country. As will be highlighted below, these students not only enjoyed the exchanges, but also learned from them. 
After participating in the Virtual Exchange, I have a better understanding of cultural differences and perceptions

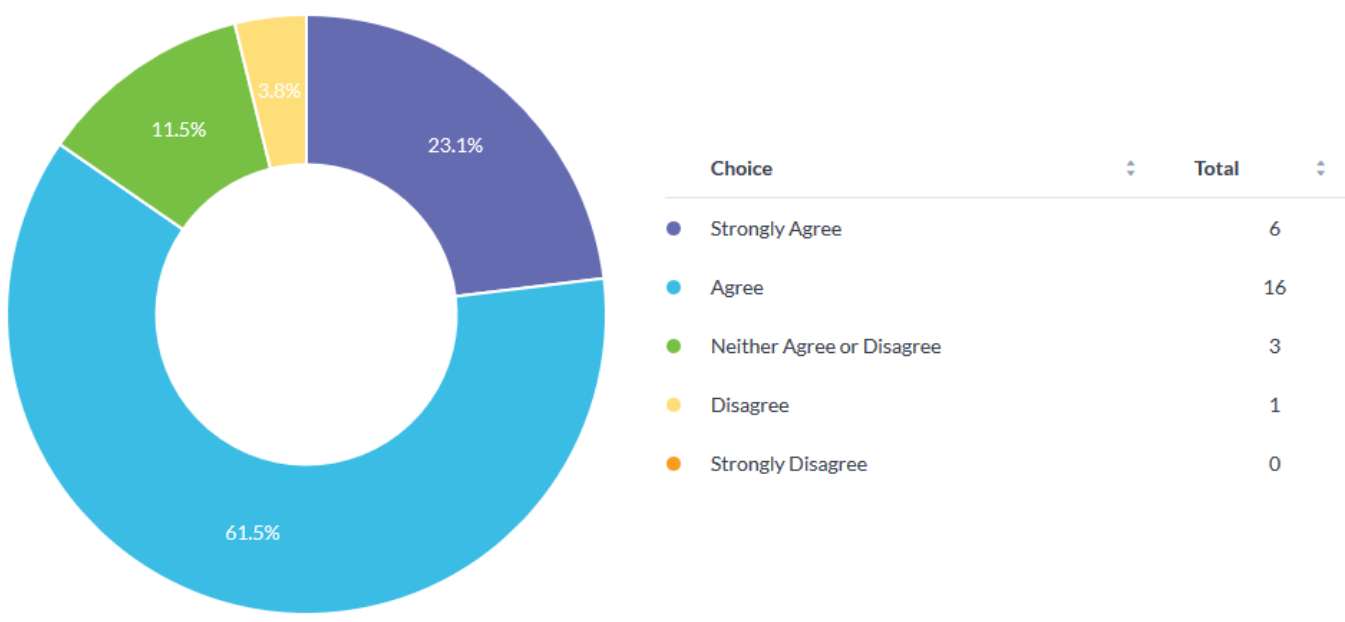

Figure 1. Cultural differences and perceptions

When considering the results of the exchanges on the students who participated, Figure 1 shows that the greater majority of the students felt that the exchanges helped them gain a better understanding of cultural differences. When combining the students who responded that they agreed or strongly agreed with the above statement, $84.6 \%$ said that their understanding of other cultures and their perceptions increased. This was one of the goals of the authors when the exchanges began, and should be a goal of any type of intercultural experiences for students.

After participating in the Virtual Exchange, I have a better understanding of how various cultures of this world interact socially

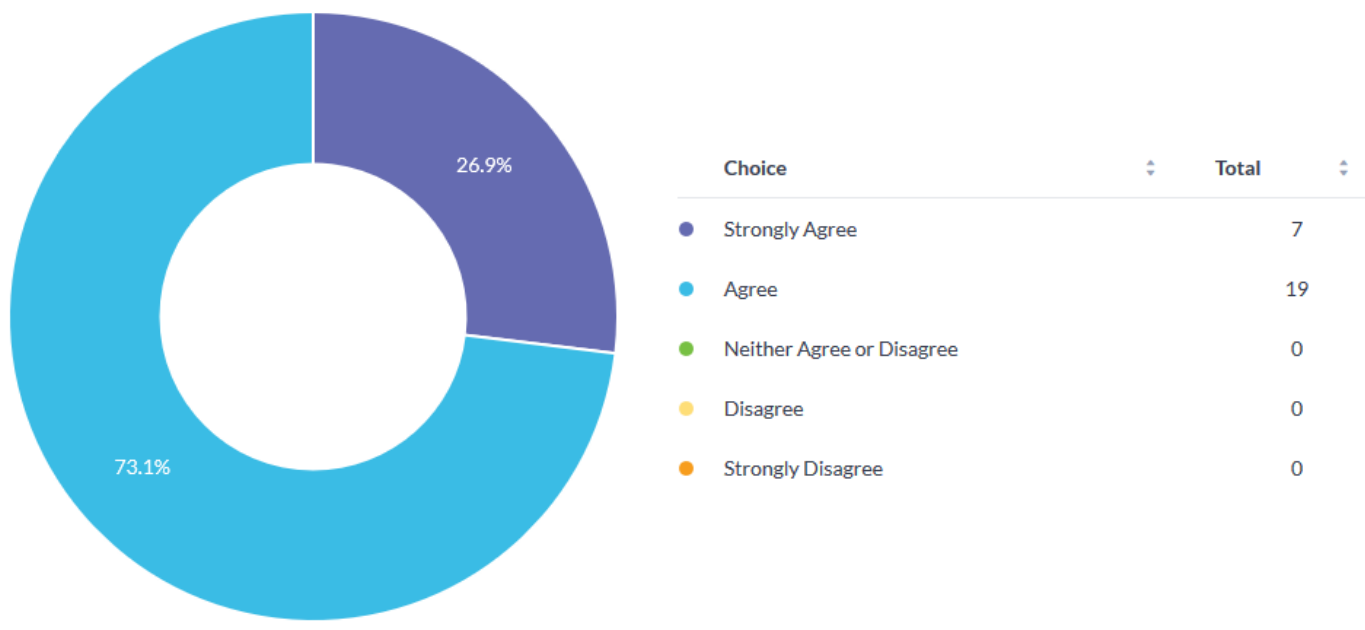

Figure 2. Social interaction

\section{After participating in the Virtual Exchange, I plan to consider different cultural perspectives when evaluating global problems}

Figures 2 and 3 show that the students grew in intercultural competence as a result of the exchanges. All the students responded that they either agree or strongly agree that as a result of the exchanges they have a better understanding of how various cultures interact socially. Several times throughout the exchanges, the students mentioned that they realized that even though they were half across the world from each other, it was easy for them to communicate and become friends and colleagues. A couple of sessions highlighted not differences, but similarities that the students shared. They were amazed at similar interests in music and food. 


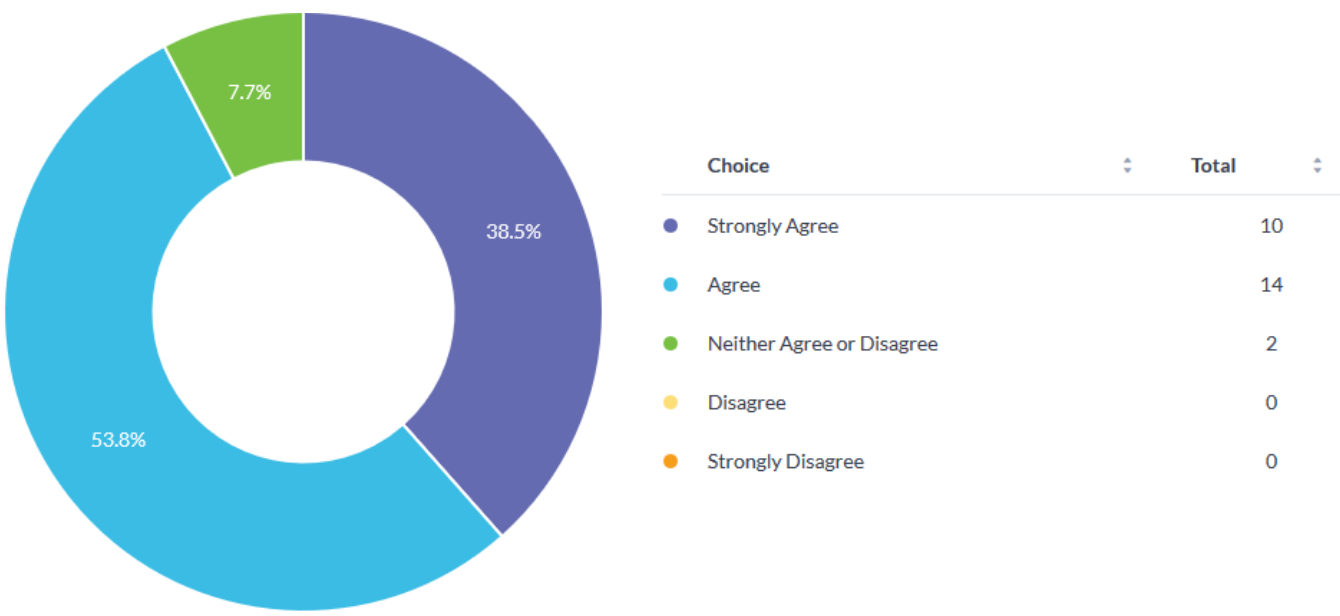

Figure 3. Different perspectives when evaluating global problems

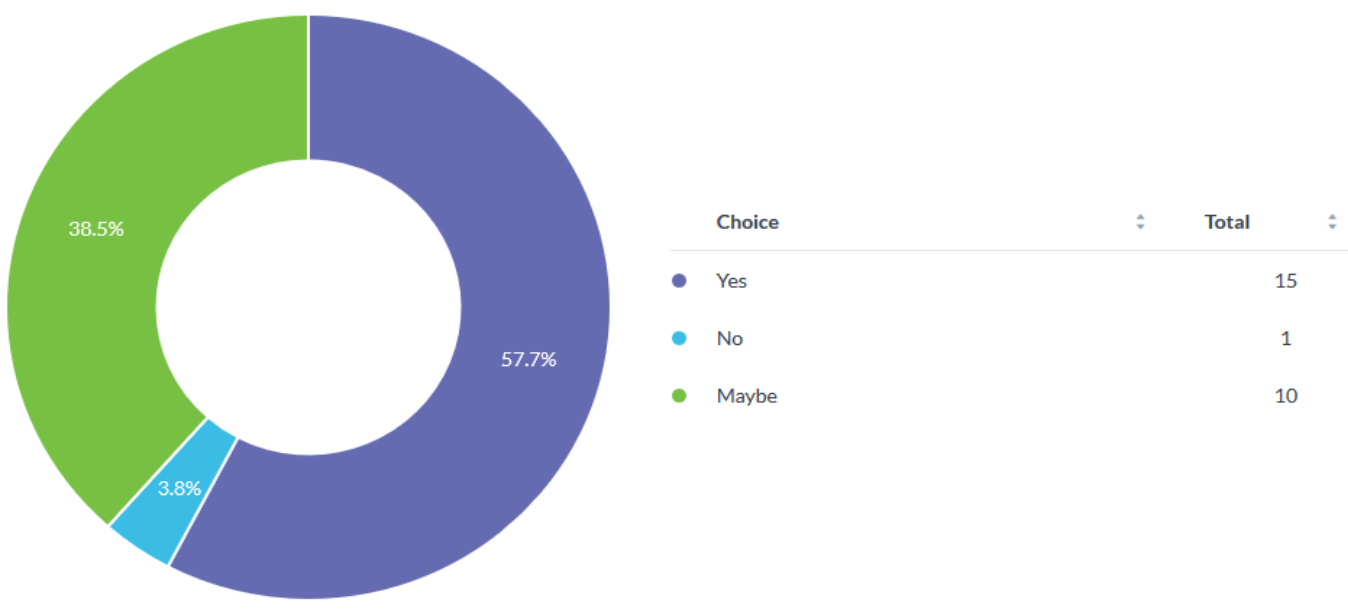

Figure 4. Likely to participate in study abroad

Figure 3 specifically shows that the students experienced different cultural perspectives and now see that these different perspectives exist. Only two students were neutral about this survey question. All of the others (92.8\%) either agreed or strongly agreed that they now have a better understanding of cultural differences and perspectives. Again, a growth in intercultural competence was seen in the students' lives as a result of the exchanges.

\section{After participating in the Virtual Exchange, I am more likely to participate in a Study Abroad experience to another country}

Figure 4 shows that the students were likely to study abroad after participating in the exchanges. The large number of students that answered that they might study abroad could be explained by the attendance of the community college students. Students at community colleges often do no study abroad or even consider it. The fact that so many said maybe shows that the thought of study abroad participation is now being considered.

From the information the authors received, the main reasons why students decided to participate in the Virtual
Exchange are: "An opportunity to learn new things", "I wanted to check my English speaking skills", "Because I could communicate with foreigners and understand their culture, type of thinking, to compare each other's differences and similarities", "To learn about Russia and how they are coping during covid-19 and how school works there".

Here are students' statements regarding the things they liked the most about the Virtual Exchange: "Opportunity to talk with people from another country", "There were diverse perspectives on different topics", "Being able to talk to people I normally wouldn't have", "I really liked everything that had happened there. The fact that we live on different continents but love the same music- it's really great".

\section{Challenges}

American and Russian colleagues faced a number of challenges in organizing joint classes. Firstly, all participants in the virtual exchange must have proper equipment: earphones, web-cameras, microphones. It is 
necessary to check the operation and set up the equipment in advance, before the start of classes. Secondly, it is very important to have a stable Internet connection. The third task is to choose the optimal time for conducting classes due to the seven-hour time difference between St. Petersburg and North Carolina. SPbSUT and DCCC have different academic schedules: the academic year begins in September and consists of 2 semesters in Russia, and academic year begins in August and is divided into quarters in the USA. The fifth challenge is that the DCCC students often used colloquial phrases which made it difficult for the Russian students to understand.

For the Russian students this opportunity provided a unique opportunity for them to learn new English skills while listening to and understanding native English speakers. The final challenge was dealing with the fact that virtual exchanges are not as true of an exchange as face-to-face exchanges. Although there was a connection made among the students, it was not as much of a connection that would have been made with in-person exchanges.

Online-classes also have a number of advantages. The first advantage is that the institutions had minimal investment in order to make the exchanges happen. Both institutions already had the equipment and internet infrastructure to allow the exchanges to take place. Although both institutions would like to purchase more equipment to allow the exchanges to run more seamlessly, no equipment had to be purchase to run the exchanges.

The exchanges also allowed the instructors to have a flexible schedule. Because the exchanges could happen at any time, there was great flexibility for both the instructors and the students. For both institutions the exchanges were a great opportunity to encourage student participation in study abroad. Both SPbSUT and DCCC offer study abroad opportunities for their students. These exchanges provided a great encouragement for the students to study abroad.

In addition, students, without leaving their countries, had the opportunity to establish professional and personal contacts with people from another country and get a cross-cultural experience. This has been important during the world pandemic. Many study abroad opportunities were cancelled. These exchanges provided many students the opportunity to establish these contacts without having to travel. The exchanges also provided students who normally could not travel an opportunity to establish contacts with people in another country. This became one of the most important benefits of the exchanges.

\section{Conclusions}

The exchange data from SPbSUT and DCCC's collaboration aligned with the previous research in that
COIL exchanges are beneficial for participants. The data that was collected showed that the students from SPbSUT and DCCC gained intercultural competence and a desire to participate in future study abroad programs. Students also commented about their belief that intercultural exchanges should be included in the curriculum. These data points show that students can make gains even through virtual cultural exchanges.

Even though COVID-19 interrupted the schedule that SPbSUT and DCCC had for participating in exchanges, the institutions were able to make a quick pivot and move the exchanges to a virtual format. Both SPbSUT and DCCC found that the virtual exchanges provided benefits for the students and the institutions international programs. With the travel difficulties that institutions still face because of the pandemic, the virtual exchanges that SPbSUT and DCCC participated in could be a viable alternative for others. These exchanges will continue even if travel between the countries becomes easier because of the success that both institutions experienced.

\section{Acknowledgements}

We are very grateful to the Fulbright Program for making the possibility of these exchanges happen. Without the introduction provided for by the program, none of this intercultural learning by students in Russia or the United States would have been possible.

\section{REFERENCES}

[1] Mapp, S.C. (2012). Effect of short-term study abroad programs on students' cultural adaptability. Journal of Social Work Education. 48(4), 727-737

[2] Fry, G.W., Paige, R.M., Jon, J., Dillow, J., \& Nam, K. (2009). Study abroad and its transformative power (Occasional Papers on International Education Exchange, No.32).

[3] Cifuentes, L., \& Yu-Chih, D., (2001). Teaching and Learning online: A Collaboration Between U.S. and Taiwanese Students. Journal of Research on Technology in Education, 33(4), 456 - 474

[4] NCCS. (2020). "Mission \& History." Retrieved from https://www.nccommunitycolleges.edu/mission-history

[5] Whatley, M. (2020). International Education at North Carolina Community Colleges. Belk Center for Community College Leadership and Research, North Carolina State University.

[6] Asojo, A., Kartoshkina, Y., Amole, D. \& Jaiyeoba, B. (2019). Multicultural Learning and Experiences in Design Through the Collaborative Online International Learning (COIL) Framework. Journal of Teaching and Learning with Techonology, 8(Special Issue), 5 - 16. 
[7] Vahed, A. \& Levine, S. Collaborative Online International Learning: A Pedogogical Intervention to Enrich Students' Learning. European Conference on e-Learning; Kidmore End, (2019).

[8] Guth, S. (2013). The COIL Institute for Globally Networked Learning in the Humanities. Retrieved from https://www.suny.edu/global/coil

[9] The Corona Virus Crisis and the Future of Higher Education. Retreived from https://info.qs.com/rs/335-VIN-535/images/ the-coronavirus-crisis-and-the-future-of-higher-education.p df 